\title{
A Kick in the Pants: Influence of Dark-Triad Personality Traits and Gender on Violence Intention among Teenagers in Yobe State, Nigeria
}

\author{
Samuel Sunday Fasanmi ${ }^{1}$, Adeoye Emmanuel Olusegun ${ }^{2}$, Mahmood Danasabe ${ }^{1}$ \\ ${ }^{1}$ Department of Psychology, Federal University Gashua, Gashua, Nigeria \\ ${ }^{2}$ Department of Family Medicine, Ladoke Akintola University, Ogbomosho, Nigeria
}

Email address:

fasanmisamuel@yahoo.com (S. S. Fasanmi), adeoyeayegbusi@gmail.com (A. E. Olusegun), danasabemahmood@gmail.com (M. Danasabe)

\section{To cite this article:}

Samuel Sunday Fasanmi, Adeoye Emmanuel Olusegun, Mahmood Danasabe. A Kick in the Pants: Influence of Dark-Triad Personality Traits and Gender on Violence Intention among Teenagers in Yobe State, Nigeria. Psychology and Behavioral Sciences.

Vol. 9, No. 4, 2020, pp. 56-60. doi: 10.11648/j.pbs.20200904.14

Received: July 27, 2020; Accepted: August 6, 2020; Published: August 19, 2020

\begin{abstract}
The study examined the influence of the dark triad personality traits (Machiavellianism, narcissism and psychopathy) and gender on violent intentions among teenagers. The design adopted for the study is the survey design. A total of 300 participants took that cut across the three Senatorial districts of Yobe State participated in the study. The subejects were examined on a battery of standardized psychological tests. The sample comprised of $155(51.7 \%)$ male and $145(48.3 \%)$ female, standardized paper and pencil questionnaire was employed for data collection. The influence of the dimensions of the dark triad personality traits (Machiavellianism, narcissism and psychopathy, and gender and socioeconomic status were examined on the violent intention of the teenagers using hierarchical regression analysis. The results showed that each independent variable can jointly and independently predict violent intentions. It was recommended that government, law enforcement agencies, psychologists, teachers and individuals should be aware of the relationship existing between dark triad personality traits, aggression and violent intentions so as to reduce deviant behaviours and handle criminals appropriately.
\end{abstract}

Keywords: Dark Triad Personality Traits, Gender, Violence Intention

\section{Introduction}

North-East Nigeria continues to be hotspot for a significant humanitarian crisis, resulting from the ongoing armed conflict between Boko Haram, the Nigerian military, and the Multi-National Task Force. In 2020, the violent conflict in North-East Nigeria entered its eleventh year and indications suggest that the crisis will progress into the near future. It is no doubt that the conflict has bred widespread displacements, violations of international humanitarian and human rights law, protection risks, and an ever-growing humanitarian crisis. An estimated 1.8 million people remain internally displaced by the conflict and 200,000 have sought refuge in neighboring countries of Cameroon, Chad, and Niger [1]. The United Nations Office for the Coordination of Humanitarian Affairs [2] reported that an about 5,000 IDPs may have arrived to Geidam, Gashua and Nguru from November to December 2019; most of whom arrived over the past two weeks in December.

Youth are usually at the receiving end of the population in most of the conflict and displacement prone contexts within which Danish Refugee Council-Danish Demining Group (DRC-DDG) operate, and North-East Nigeria is no exception, where young people account for many of those adversely affected by the conflict as it has disrupted their access to education and social services. Some have been subjected to overwhelming violence that will have a longterm impact on their psychological well-being [3].

Youth violence is a serious global public health problem. Homicide rates are again rising and continue to claim the lives of many young people. The human and economic toll of violence on young people, their families, and society is high. Homicide is the second leading cause of death for persons 15-24 years of age and has been the leading cause of death for African and Americans in this age group for over a decade. The economic cost associated with violence-related 
illness, disability, and premature death is estimated to be in the billions of dollars each year.

The dark triad is a subject in psychology that focuses on three personality traits: narcissism, Machiavellianism, and psychopathy. Use of the term "dark" implies that people possessing these traits have malevolent qualities.

Machiavellianism is the social expression and manifestation of selfishness, manipulation and amoral thinking [4]. Machiavellianism is generally used to describe a person's tendency to be unemotional, manipulative, exploiting and ability of individuals to detach themselves from conventional moral behaviours. Machiavellians are individuals with high tendency to deceive and manipulate others in order to achieve their objectives. They are also known to be cunning and scheming.

The term was used to embody and characterize the behaviours and exploits of Niccolo Machiavelli who was a statesman in the late $14^{\text {th }}$ century. Niccolo Machiavelli was known for his quick and sudden rise to the top as he was a lowborn before gaining popularity amongst other statesmen. His rise was somewhat controversial as he was cunning, manipulating and scheming while also being amoral all through his entire career as a statesman. Niccolo Machiavelli's behaviour and typical characteristics birthed and gave meaning to the term Machiavellianism. Individuals that score high on Machiavellianism use others to achieve their goals through manipulation, exploitation and deceit.

Psychopathy is characterized by high impulsivity, thrill seeking behavior and both low anxiety and empathy [5]. Psychopathic individuals show antisocial behavior, which could lead to destructive behavior towards themselves and to others. Psychopathic individuals lack guilt, remorse and empathy, so while they may perceive the distress and suffering of others, they are not actually affected by the person's suffering rather, they seem to derive pleasure from the suffering of their victims. Whereas, uncontrolled secondary psychopaths may display poor behavioural inhibition, giving rise to more generalized anti-social acts [6].

Sub clinically, psychopathic individuals exhibits many characteristics of clinical psychopathy except for some of the more severe antisocial behaviours. These individuals have impaired empathy. Sub clinical psychopathy can be related to moderated or altered expression of empathy.

Psychopathy under the scope of dark triad personality is majorly sub clinical as individuals that exhibits such traits are more or less normal and still tolerable by the society.

The last dimension of the Dark Triad is narcissism. Although narcissistic individuals tend to be grandiose, have affections of superiority, a sense of entitlement and a need for attention met through the admiration of others, narcissism is nevertheless the least socially averse dimension of the Dark Triad, this is perhaps because some expressions of narcissism may accurately reflect self-perceived competency and resilience [7].

Narcissism is often said to be an excessive interest in one's self, a sense of high self-centeredness, self-interest and a huge elevation of one's achievements, life goals or attributes even when they are regular like those of others. The word originated from the Greek mythology based on the story of a very handsome man called Narcissus who is coveted by all over the entire community but he is too full of himself and will only give his love to another that is as beautiful as himself. This behaviour led to so many controversies and also to the death of a certain nymph called Echo, who died after receiving huge insults from Narcisssus because of her advancements towards him. Echo died in abandonment leading to Narcissus being cursed. Narcissus one day fell in love with the beautiful reflection of his own image by the river side. He knelt by the reflection and wanting the reflection to love him back, he stayed there till his last breathe. Thus the term Narcissism came into play, there are lots of people who exhibits this traits as they seem to be so engrossed with themselves and become so self-absorbed, egocentric and detached from reality.

A few studies have investigated the role of the Dark Triad and normal personality in relation to violence and other explicitly hostile behaviours e.g bullying, direct and indirect aggression. The three personality constructs all seem to incorporate a malignant character with aggressive, selfpromotional, emotional chill and dissembling behavior [5]. Because of this malignant factor, several studies have been conducted examining the relationships between different traits of the dark triad, aggression and other anti-social behaviours.

Anderson and Bushman defined violence as "aggression that has extreme harm as its goal (e.g. death). Violence is "the intentional use of physical force or power, threatened or actual, against oneself, another person, or against a group or community, which either results in or has a high likelihood of resulting in injury, death, psychological harm, maldevelopment, or deprivation", although the above sentence acknowledges that the inclusion of "the use of power" in its definition expands on the conventional understanding of the word [8]. Violent behaviours in humans and their causes are often a topic research in psychology. Neurologist Jan Volavka emphasizes that, "violent behaviours are intentional physically aggressive behaviour against another person". Since violence is a matter of perception and intention, psychologists have found variability in whether people perceive certain physical acts as violent.

Likewise, understandings of violence are linked to a perceived aggressor-victim relationship, hence psychologists have shown that people may not recognize defensive use of force as violent, even in cases where the amount of force used is significantly greater than in original aggression. Although young adolescents engage in less severe violent behaviour than older adolescents, the way they perceive provocation and normative expectations to use violence to resolve conflicts may already be established by early adolescence.

The broad objective of this study was to determine the influence of dark triad traits and gender on violence intention among teenagers of Yobe State. 


\section{Methodology}

This section contains the research design, method of study, population of study, sample frame and sample size, sampling method, research instruments, method of data collection and data analysis.

\subsection{Research Design}

The study adopted a survey research method, where the variables to be investigated are dark triad traits; Machiavellianism, narcissism and psychopathy, gender, and violence.

\subsection{Population of the Study}

Population was drawn from across the three Senatorial District of Yobe States viz:. The zones include: Yobe North Senatorial Zone; Yobe Central Senatorial Zone and Yobe South Senatorial Zone. Yobe State has a population of about 2,321,591 people (NPC, 2006) out of which one third of it are teenagers.

\subsection{Sample and Sampling Procedure}

The sample was chosen from the population making use of purposive sampling method to select participants. In the first stage, three Local Government Areas were purposively selected in each zone: Bade LGA in Northern Zone, Damaturu LGA in Central and Potiskum LGA in Souththern Zone, out of the seventeen LGAs in Yobe State. This was done for easy accessibility and to cut across the State. Also, simple random sampling technique was used to select two villages from each Local Government Area, making a total of six villages used for the study. A sample size was three hundred (300) with at least $51.7 \%$ (155) of the respondent were male, while $48.3 \%$ (145) were female were accidentally selected for the study. The minimum age of respondents was 12 while the maximum was 19 years old.

\subsection{Research Instrumentation}

The questionnaire was divided into three sections. The first section which was Section 'A' addressed the personal data of the respondents while Section 'B' consisted Short Dark Triad (SD3) items for evaluating the dark triad personality traits and it was divided into three subsections for; Machiavellianism, narcissism and psychopathy respectively. The Section ' $\mathrm{C}$ ' measured violent intentions among teenagers using The Attitudes towards Violence Scale.

Dark Triad was measured using Short Dark Triad (SD3) by Jones \& Paulhus in 2014 [9]. The test instrument was developed to measure the three socially aversive traits; Machiavellianism, Narcissism and psychopathy. The scale was divided into 3 subtypes in respect to the factors and in accordance to the coordinates of the construct with each subtype housing 9 items each to give a total of 27 items. Each item generates a response subjective to the Likert type format with anchors 1 (strongly disagree) to 5 (strongly agree) as some items are also reversed.

Violent intention was measured using the Attitudes towards Violence Scale [10] University of Toledo. The ATVC is a self-report questionnaire designed to measure attitudes toward violence and violent intentions, characteristics that may mediate the transformation of anger into aggression and violence. The ATVC has good internal consistency and two factors that measure key components of violent attitudes: a general predisposition to view violence as a desirable behavioral choice, and violence in response to specific provocation. The authors reported internal reliability (Cronbach's alpha) of .78. Convergent validity was derived using the Child Empathy Questionnaire (CEQ) giving a negative $r$ of -.51 . However, for this study, an alpha reliability coefficient of 0.47 was reported.

\subsection{Method of Data Analysis}

This research adopted the statistical use of the following statistical methods to test for its research hypotheses. Hierarchical regression analysis was used to examine the dimensions of the personality and gender on the violent intentions of the selected teenagers.

\section{Results}

Table 1. Beta Value, $R^{2}$ and F Ratios for independent variables predicting violent intention among teenagers.

\begin{tabular}{llllll}
\hline Variables & Equation 1 & Equation 2 & Equation 3 & Equation 4 & Equation 5 \\
\hline Sex & $-.142^{\mathrm{x}}$ & $-.124^{\mathrm{x}}$ & $-.108^{\mathrm{x}}$ & $-.116^{\mathrm{xx}}$ & $-.132^{\mathrm{x}}$ \\
Socioeconomic Status & & $.159^{\mathrm{xx}}$ & $.240^{\mathrm{xx}}$ & $.180^{\mathrm{xx}}$ & $.194^{\mathrm{xx}}$ \\
Narcissism & & $-.296^{\mathrm{xx}}$ & $-.357^{\mathrm{xx}}$ & $-.156^{\mathrm{x}}$ & $.310^{\mathrm{xx}}$ \\
Psychopathy & & & $.301^{\mathrm{xx}}$ & $-.305^{\mathrm{xx}}$ \\
Machiavellian & & & & .244 \\
$\mathrm{R}^{2}$ & .017 & .039 & .117 & .196 & 20.307 \\
$\mathrm{~F}$ & $6.099^{\mathrm{xx}}$ & $6.989^{\mathrm{xx}}$ & $14.195^{\mathrm{xx}}$ & 19.275 & \\
\hline
\end{tabular}

Table 1 showed that sex, socioeconomic status, Machiavellianism, narcissism, aggression and psychopathy will independently and jointly predict violent intention among teenagers. Hierarchical regression analyses were performed with stepwise (forward criterion) inclusion of predictor variables. The demographic variables of sex and socioeconomic status were used as control and entered first, followed by the predictor variables. As shown in Table 1, in equation 1 sex accounted for $2 \%$ of variance in violent intention, with a regression coefficient of $\beta=-.142(\mathrm{P}<.05)$. 
This implies that sex explained $2 \%$ variance in violent intention. The negative value of the beta weight implies that male is associated with higher violent behavior. Socioeconomic status account for only $4 \%$ of the variance in violent intention $(\beta=.159, \mathrm{P}<.05)$ explaining, together with sex, $4 \%$ of the variance in violent intention (accounting for $\mathrm{R}^{2}$ - change of $\left..02, \mathrm{P}<.01\right)$. In equation 3 , the addition of narcissism $(\beta=-.296, P<.01)$ increased the variance explained by $\mathrm{R}^{2}-$ change $=.08,(\mathrm{P}<.01)$. The negative value of the beta weight implies that those who are low on narcissism are associated with higher violent behavior. In equation 4 , the addition of psychopathy $(\beta=.301, \mathrm{P}<.01)$ increased the variance by $\mathrm{R}^{2}-$ change $=.08(\mathrm{P}<.01)$. In equation 5 , the addition of Machiavellianism $(\beta=-.305, \mathrm{P}$ $<.05)$ increased the variance explained by $\mathrm{R}^{2}-$ change $=.05$, $(\mathrm{P}<.01)$. The negative value of the beta weight implies that the lower the perceived Machiavellianism among teenagers, the higher their level of violent intention.

The results showed the joint and independent impact of each independent variables on the prediction of violent behaviours and intentions. It was discovered that each independent variable brought about a positive change in violent behaviours which also explains how male are found to be more violent compared to female. The study also explained the joint influence of every independent variable on violent intentions.

\section{Conclusion}

In line with one of the hypotheses of this study which stated that there will be a significant relationship between the dark triad personality traits and aggression, the outcome of the research revealed that each constructs of the dark triad personality traits were positively related to aggression. This confirms the statement by (Martin, Lastuk, Jeffrey, Vernon, \& Veselka in 2012 that Machiavellians and psychopaths prefer aggressive humor styles meaning Machiavellianism and psychopathy are in fact related to aggression. Investigation on psychopathy was said by Cleckey to have begun with studies of repeat criminals, aggressive behaviours and violent acts [11]. Hence, this supports the second and first hypotheses which tested the relationship between dark triad personality traits (Machiavellianism, narcissism and psychopathy), aggression and violent intentions. Hence, it is not surprising that psychopaths are known as bullies and aggress after physical threats [9], and carry out deviant fantasies. Their research also found that psychopaths responds more aggressively to physical threats compared to other traits of the triad. This is in line with the result of this research as the results showed a positive relationship between psychopathy and aggression which also explains the positive relationship between psychopathy and violent intentions. Both hypotheses testing the relationship between the dark triad personality traits (Machiavellianism, narcissism and psychopathy), aggression and violent intentions were accepted.

Also in line with the testing done in this research, the study of Barry, Frick and Killian agrees and supports the result of this research as they found that maladaptive narcissism is related to children's and adolescents aggression [12]. Another research that has previously linked dark triad personality traits to aggression and violent intentions was the study of Hemphill et al as they found that psychopathy is positively related to increased aggression and violent behaviours.

There is shallow knowledge about the personality traits of criminals in the country's method of handling terrorists and criminals who have perpetrated several heinous and destructive deeds. The government has not utilized the health professionals especially the psychologists expertise in this area. This has grievously dampened the external and internal image of the country and has led to the nation being listed amongst the highly violent nations. This research is recommended to government agencies as well as all law enforcement agencies as it helps in explaining the relationship between the dark triad personality traits and violent intentions among adolescents which can also be adapted to adults by other researchers.

\section{References}

[1] European Commission (2017). EU Emergency Trust Fund for Africa https://ec.europa.eu/trustfundforafrica/all-news-andstories/youth-empowered-and-safe-youth-driven-communityempowerment-north-east-nigeria_en

[2] United Nations Office for the Coordination of Humanitarian Affairs (2020). Yobe State | Humanitarian Situation Overview - 10 January $2020 \mathrm{https}: / /$ reliefweb.int/report/nigeria/yobestate-humanitarian-situation-overview-10-january-2020

[3] Fasanmi, S. S., Kaburuk, D. S., \& Ariyo, A. B. (2015). Influence of psycho-social factors on youths' attitude towards internet fraud in Nigeria. Procedia-Social and Behavioral Sciences (182) 110-115. Elsivier.

[4] Rauthmann \& Kolar, (2012). How “dark" are the Dark Triad traits? Examining the perceived darkness of narcissism, Machiavellianism, and psychopathy. Personality and Individual Differences 53 (7): 884-889. DOI: 10.1016/j.paid.2012.06.020.

[5] Paulhus, D. L, \& Williams, K. M. (2002). The Dark Triad of personality: Narcissism, perceived darkness of narcissism, Machiavellianism, and psychopathy. Personality and Individual Differences, 53, 884-889.

[6] Glenn, A. L., Iyer, R., Graham, J., Koleva, S., \& Haidt, J. (2009). Are all types of morality compromised in psychopathy? Journal of Personality Disorders, 23, 384-398.

[7] Egan, V., Chan, S., \& Shorter, G. W. (2014). The Dark Triad, happiness and subjective well-being. Personality and Individual Differences, 67, 17-22. https://doi.org/10.1016/j.paid.2014.01.004

[8] Anderson, C. A. \& Bushman, B. J. (2002). Human Aggression. Annual Review of Psychology 53 (1): 27-51.

[9] Jones, D. N., \& Paulhus, D. L. (2014). Introducing the Short Dark Triad (SD3): A Brief Measure of Dark Personality Traits. Assessment, $21 \quad$ (1), 28-41. https://doi.org/10.1177/1073191113514105 
[10] Funk, J. B., Elliott, R., Urman, M. L., Flores, G. T., \& Mock, R. M. (1999). The Attitudes Towards Violence Scale: A Measure for Adolescents. Journal of Interpersonal Violence, 14 (11), $1123-1136$. https://doi.org/10.1177/088626099014011001

[11] Martin, R. A., Lastuk, J. M., Jeffrey, J., Vernon, P. A., \& Veselka, L. (2012). Relationships between the Dark Triad and humor styles: A replication and extension. Personality and Individual Differences, 52, 178-182.

[12] Barry C. T., Frick P. J., Killian A. L. (2003). The relation of narcissism and self-esteem to conduct problems in children: a preliminary investigation. Journal of Clinical Child Adolescence Psychology. 32 (1): 139-152. doi: 10.1207/S15374424JCCP3201_13. 